\title{
Utilization of isoniazid prophylaxis therapy and its associated factors among HIV positive clients taking antiretroviral therapy at Fre Semaetat primary hospital, Hawzien districts, Tigrai, Northern Ethiopia
}

Haftom Legese ${ }^{1 *}$, Hagos Degefa ${ }^{2}$, Aderajew Gebrewahd ${ }^{1}$ and Haftay Gebremedhin ${ }^{2}$

\begin{abstract}
Background: Isoniazid prophylaxis therapy is a significant public health intervention to prevent the progression of latent tuberculosis to active tuberculosis disease among people living with HIV. Those with HIV are at high risk to develop active Tuberculosis from latent Tuberculosis than those without HIV. Even though there is strong evidence supporting Isoniazid Prophylaxis therapy for Tuberculosis prevention, there is limited information about the implementation of isoniazid prophylaxis therapy in Ethiopia as well as in the study area.

Objective: To determine the effects of Isoniazid Prophylaxis therapy and its associated factors among HIV positive clients taking antiretroviral therapy at Fre Semaetat primary Hospital, Hawzien districts, Tigray, northern Ethiopia. Method: Institutional based cross-sectional study design was conducted from April to August 2019 among HIV positive clients who came to Fre Semaetat primary Hospital. Data related to socio-demographic characteristics and associated risk factors were taken from 372 HIV positive clients who were selected by a simple random sampling method. Data was coded and cleaned by using SPSS version 23.0 for the final analysis.
\end{abstract}

Results: A total of 372 HIV positive clients taking antiretroviral therapy were included in the study. Of those, the overall prevalence that took and completed their Isoniazid Prophylaxis therapy for 6 months was found to be $231(62.1 \%)$. From those who completed Isoniazid Prophylaxis therapy (IPT), 13(3.5\%) was developed active Tuberculosis (TB) incidence. Gender, co-trimexazol Prophylaxis therapy users, HIV positive clients who took Anti-pain and married clients were the predictor among statistically significant variables of Isoniazid Prophylaxis therapy.

Conclusions: Isoniazid Prophylaxis therapy utilization found to below. Therefore, health education and counseling of patients who are in their first 2 months of therapy should be strengthened further. Prophylaxis should be given by service providers, medication side effects should be addressed rapidly.

Keywords: Isoniazid prophylaxis, HIV positive, Antiretroviral therapy, Ethiopia

\footnotetext{
* Correspondence: legesehaftom2@gmail.com

'Department of Medical Laboratory Sciences, College of Medicine and Health Sciences, Adigrat University, Adigrat, Ethiopia

Full list of author information is available at the end of the article
}

(c) The Author(s). 2020 Open Access This article is licensed under a Creative Commons Attribution 4.0 International License, which permits use, sharing, adaptation, distribution and reproduction in any medium or format, as long as you give appropriate credit to the original author(s) and the source, provide a link to the Creative Commons licence, and indicate if changes were made. The images or other third party material in this article are included in the article's Creative Commons licence, unless indicated otherwise in a credit line to the material. If material is not included in the article's Creative Commons licence and your intended use is not permitted by statutory regulation or exceeds the permitted use, you will need to obtain permission directly from the copyright holder. To view a copy of this licence, visit http://creativecommons.org/licenses/by/4.0/. The Creative Commons Public Domain Dedication waiver (http://creativecommons.org/publicdomain/zero/1.0/) applies to the data made available in this article, unless otherwise stated in a credit line to the data. 


\section{Background}

Tuberculosis (TB) remains a major public health concern particularly in those countries with poor access to resources $[1,2]$. It is the ninth leading cause of death worldwide and the leading cause of a single infectious agent, ranking above HIV/AIDS [3]. The risk for TB is 20-37 times greater among persons infected with HIV comparing to those who do not have HIV infection [4].

The proportion of TB and HIV co-infection is highest in African countries. Overall, the African region accounted for $82 \%$ of TB cases among HIV positive individuals in some countries in sub-Saharan Africa, up to 1.68 million killed by TB infection, 0.38 million death were HIV positive [5]. Ethiopia is among the high TB/HIV burden countries with estimated incidence and prevalence of TB 207 and 200 per 100,000 populations as co-infection among HIV positive clients respectively [6].

TB transmission and control measure has faced challenges due to co-infection with HIV. HIV and TB service delivery is insufficiently integrated, and too many people are losing their lives because they are unable to either prevent TB or access life-saving medications for both diseases $[7,8]$. Therefore, establishing and strengthening of coordination mechanisms for the providing of ART and Isoniazid Prophylaxis therapy (IPT) to people living with HIV who do not have active TB is essential in order to prevent the transmission and develop of active TB infection $[9,10]$.

Despite substantial evidence about the effect of IPT or IPT-ART combination therapy in HIV patients, the global utilization rate is far lower than would be expected. Provision of isoniazid preventive therapy (IPT) is one of the public health interventions for the prevention of TB in HIV infected individuals. Even though, According to 2014 WHO report that only $41 \%$ of eligible HIV patients used IPT which is very low coverage [11].

However, in Ethiopia, the coverage and implementation of IPT are limited as previous research is done [12], and there is no published data in the study area. Therefore, this current study would be important to determine the effectiveness of the provision of IPT for HIV infected individuals in preventing occurrence of TB in the study area.

\section{Methods}

\section{Study design, period and area}

The institutional-based cross-sectional study design was conducted from April to August 30, 2019. This study was conducted in Fre Semaetat primary hospital, Tigrai, North Ethiopia. Which is located $867 \mathrm{~km}$ far from Addis Ababa capital city of Ethiopia to north direction and $107 \mathrm{~km}$ to east direction from Mekelle which is the capital city of Tigrai region. Based on the 2007 national census conducted by the central statistical agency of Ethiopia (CSA), this district had a total population of 117,954 , of whom $47.8 \%$ men and $52.2 \%$ were women.

\section{Eligibility criteria}

HIV positive clients who did not develop active TB based on the TB screening criteria were considered as inclusion criteria.

\section{Exclusion criteria}

In a client who had incomplete data records (patients who lost during follow up, absence of client's medical, clinical and laboratory values). Clients who were transferred out from the study area to other health facilities were excluded from the study. Clients already developed TB/HIV co-infection from the documentation.

\section{Sample size determination and sampling procedure}

The sample size was determined using the single population proportion formula.

$$
\mathrm{n}=\frac{\mathrm{Z}^{2} \alpha / 2 \mathrm{P}(1-\mathrm{P})}{\mathrm{d}^{2}}
$$

By the prevalence of IPT from the previous study done in Arbaminch hospital, South Ethiopia (68\%) which was done by Ashenafi A, [13]. Then with a margin of error (5\%), $(d=0.05)$ and 95\% level of confidence $(z=1.96)$.

The total 372 was selected Using a simple random sampling technique to select study participants.

\section{Study variables \\ Dependent variables}

Utilization of IPT.

\section{Independent variables}

Client related factors, Socio-demographic variables including (Age, Sex, Religion, educational status, marital status, and occupational status) adherence of IPT, social drug use, Drug factors, ART, CPT, anti-pain medication, anthelmintic, and antifungal.

Disease factors, OIs, WHO clinical stage, CD4 count, BMI, and viral load.

\section{Data collection instruments}

Quantitative data was collected through intervieweradministered Face to face technique and were collected from HIV care/ART follow-up clients in ART clinic as well as laboratory data using a structured questionnaire such as socio-demographic characteristics (Age, Sex, Religion, educational status, marital status, and occupational status), medication-related factors (social drug use, Drug factors, ART, CPT, anti-pain medication, anthelmintic, and antifungal) and included based on IPT status, and patients who had a registered baseline such 
as disease factors (OIs, WHO clinical stage, CD4 count, BMI, and viral load). The questionnaire was adopted from Ethiopia and Tanzania published articles [13, 14].

\section{Data quality control}

To attain the data quality control issue training was given for data collectors and supervisors using the local language. Questionnaires originally developed in English then translated to local language (Tigrigna) and backtranslated to English by a different translator who was blinded to the original questionnaire to check for its consistency. Three data collectors were selected from a different facility qualified in bachelor of public health officer and experience of a minimum of 3 years in the HIV clinic. The training was given using lecture and demonstration on data collection procedure and supervision was given for 2 days. The questionnaire was pre-tested $5 \%$ of the total sample size at different facilities involving enumerators and supervisors and data was collected at the study hospital.

The principal investigator and supervisors on a daily basis checked and visit to review questionnaires' completeness, accuracy and consistency and corrective discussion was undertaken with research team members on gaps identified. A reminding remark was given during each morning by the supervisor on how to minimize errors and timely corrective actions were taken. Two data clerks did double data entry and consistency of the entered data was crosschecked by comparing the two separately entered data on Epi-Data version 3.02.

\section{Data processing and analysis}

After the data collected and checked for its completeness, it was coded, entered and cleanedusing EPI-data software version 3.1 then exported to SPSS software version 23 for analysis. Descriptive statistics like frequency, percentage, measures of central tendency and measures of dispersion were carried out. Missing values were analyzed by using multiple imputation techniques. Then the information was presented using frequencies tables and figures. Chi-square test $\left(\mathrm{X}^{2}\right)$ and $\mathrm{Bi}$-variable logistic regression analysis were done for each variable and variables with their $p$-value $<0.025$ were taken to the multivariable analysis to control all possible confounders. The multi co-linearity test was carried out to see the correlation between independent variables using standard error. In the multivariable logistic regression analysis, the model fitness test was checked using Hosmer and Lemeshow test. Odds ratios along with 95\% CI were used to measure the association between the dependent and independent variables and the level of statistically significant was declared at $p$-value $<0.05$.

\section{Ethical consideration}

Ethical approval was obtained from the Institutional Health Research Ethics Review Committee (IHREC) of, Adigrat University College of Health and Medical Sciences. A written officiala letter was taken from IHREC to Hawzen district Health Bureau to deem its legality.After getting permission a written official letter was also taken to director of the Fre Semaetat primary Hospital, Hawzen administrative offices and then to the ART clinic officer for permission. The confidentiality of information was secured and no personal identifier was included in the data collection tool.

\section{Results}

\section{Socio-demographic data}

A total of 372 study subjects were included in the study. The majority of $200(53.80 \%)$ respondents were male. Of the total study participants, $252(67.70 \%)$ were aged above 34 years. The mean age of the participants was $37.94 \pm 12.15$, and the median age was 39 . Most of the $306(82.30 \%)$ of the study participants were Orthodox religions followed by Muslim 66 (17.70\%). Two hundred twenty-three $(59.90 \%)$ study participants were unable to read and write. While 149 (40.10\%) participants have educated college and above. Among the study participants, 284 (76.30\%) were married (Table 1).

Table 1 Socio-demographic characteristics of the study participants in Fre Semaetat primary Hospital Hawzen, Tigrai, Ethiopia from April to August $2019(N=372)$

\begin{tabular}{|c|c|c|c|}
\hline \multicolumn{2}{|c|}{ Socio-demographic characteristic's } & \multirow{2}{*}{$\begin{array}{l}\text { Frequency } \\
200\end{array}$} & \multirow{2}{*}{$\begin{array}{l}\text { Percent } \\
53.80\end{array}$} \\
\hline Sex & Male & & \\
\hline & Female & 172 & 46.20 \\
\hline \multirow[t]{4}{*}{ Age } & $0-14$ & 16 & 4.30 \\
\hline & $15-24$ & 35 & 9.40 \\
\hline & $25-34$ & 69 & 18.50 \\
\hline & $>=35$ & 252 & 67.70 \\
\hline \multirow[t]{3}{*}{ Religion } & Orthodox & 306 & 82.30 \\
\hline & Muslim & 66 & 17.70 \\
\hline & Protestants & 0 & 0 \\
\hline \multirow[t]{4}{*}{ Marital status } & Married & 284 & 76.30 \\
\hline & Single & 53 & 14.20 \\
\hline & Divorced & 25 & 6.70 \\
\hline & Widowed & 10 & 2.70 \\
\hline \multirow[t]{4}{*}{ Educational level } & Cannot read and write & 223 & 59.90 \\
\hline & Primary & 109 & 29.30 \\
\hline & Secondary & 38 & 10.20 \\
\hline & College and above & 2 & 0.50 \\
\hline
\end{tabular}


Clinical, immunological and laboratory values Chi-square test $\left(\mathrm{X}^{2}\right)$ showed that WHO clinical stage $(p<0.002)$, and $\mathrm{CD} 4$ count $(p<0.01), \operatorname{Hgb}(p<0.009)$, weight $(p<0.001)$ and adherence to ART $(p<0.02)$ were statistically significant with IPT utilization (Table 2).

\section{Drug-related information}

Majority 291(78.20\%) of the respondents were received their CPT and 290 (78.00\%) study participants were also used anti-pain. All of the participants were taking ART medications, of which $187(85 \%)$ were on TDF/3TC/EFV based regimen (Fig. 1).

\section{Opportunistic infections (Ols)}

From the total respondents, 241(64.80\%) of clients developed opportunistic infections after they taking ART medication. Among the total OIs, 80(33.20\%), were community-acquired pneumonia and $51(21.16 \%)$ were URTI (Fig. 2).

\section{Completion rate of IPT for 6 months duration}

The proportion of HIV positive clients who took and completed for 6 months of their IPT prophylaxis was 231(62\%), among those 13(3.5\%) participants developed TB. Of the $13 \mathrm{~TB}$ positive individuals, 11(84.6\%) were developed TB before completing their IPT and 2 (15.40\%) were developed TB after completing their IPT (Fig. 3).

\section{Factors associated with IPT}

Bivariate and multivariate logistic regression analyses were performed to assess the association between dependent and independent study variables. According to the bivariate analysis: being female, social drug use, age, marital status, CPT, anti-pain, and antifungal were showed association with IPT and transported to multivariate analysis. Multivariate logistic regression was done to assess the association between the socio-demographic variable, medication and IPT utilization. Sex, anti-pain, marital status, and CPT had statistically significant and were independently associated with IPT utilization. Being males (AOR $=0.034,95 \% \mathrm{CI}$ : $0.015-0.077)$. Use of (AOR $=8.693$, 95\%CI: 3.600-20.991). HIV positive clients who took Anti-pain (AOR $=3.59,95 \%$ CI: 1.162-11.109). Being Married (AOR $=0.335,95 \% \mathrm{CI}: 0.140-0.806$ ) ] was significantly associated with IPT (Table 3 ).

\section{Discussion}

Isoniazid preventive therapy has been one of the four main strategies of TB prevention in both HIV positive

Table 2 Baseline clinical characteristics of clients on IPT among HIV positive clients in Fre Semaetat primary Hospital Hawzen, Tigray, Ethiopia from April to August $2019(N=372)$

\begin{tabular}{|c|c|c|c|c|c|}
\hline \multicolumn{2}{|c|}{ Baseline clinical characteristics } & \multicolumn{2}{|l|}{ IPT take } & \multirow[t]{2}{*}{ Total } & \multirow[t]{2}{*}{$P$-value } \\
\hline & & Yes & No & & \\
\hline \multirow[t]{4}{*}{ WHO C/S } & One & $238(74.1)$ & $42(82.40)$ & 280 & \multirow[t]{4}{*}{$0.002^{*}$} \\
\hline & Two & $67(20.9 \%)$ & $9(17.6 \%)$ & 76 & \\
\hline & Three & $3(0.9)$ & $0(0.0 \%)$ & 3 & \\
\hline & Four & $13(4.0)$ & $0(0.0 \%$ & 13 & \\
\hline \multirow[t]{3}{*}{ CD4 Count } & $<350$ & $94(29.3 \%)$ & $14(27.5 \%)$ & 108 & \multirow[t]{3}{*}{$0.010^{*}$} \\
\hline & $350-499$ & $156(48.6 \%)$ & $27(152.9 \%)$ & 183 & \\
\hline & $>=500$ & $71(22.1 \%)$ & 10(19.6\%) & 81 & \\
\hline \multirow[t]{3}{*}{ BMI } & $<18$ & $91(28.3 \%)$ & $8(15.7 \%)$ & 99 & \multirow[t]{3}{*}{0.094} \\
\hline & $18-25$ & $216(67.3 \%)$ & $42(82.4 \%)$ & 258 & \\
\hline & $>=25$ & $14(4.4 \%)$ & $1(2.0 \%)$ & 15 & \\
\hline \multirow[t]{2}{*}{ Hgb } & $<12 \mathrm{mg} / \mathrm{dl}$ & 39(12.\%) & $0(0.0)$ & 39 & \multirow[t]{2}{*}{$0.009^{*}$} \\
\hline & $>=12 \mathrm{mg} / \mathrm{dl}$ & $282(87.9 \%)$ & $51(100.0 \%)$ & 333 & \\
\hline \multirow[t]{4}{*}{ Weight } & $<40 \mathrm{~kg}$ & $34(10.6 \%$ & $0(0.0)$ & 34 & \multirow[t]{4}{*}{$0.000^{*}$} \\
\hline & $40-49$ & $209(65.9 \%)$ & $29(56.9 \%)$ & 238 & \\
\hline & $50-59$ & $56(17.4 \%)$ & $21(41.2 \%)$ & 77 & \\
\hline & $>60$ & $22(6.9 \%)$ & $1(2.0 \%)$ & 23 & \\
\hline \multirow[t]{3}{*}{ Adherence to ART med. } & Good & $200(62.3 \%)$ & $34(66.7 \%)$ & 234 & \multirow[t]{3}{*}{$0.020^{*}$} \\
\hline & Fair & $80(24.9 \%$ & $17(33.3 \%)$ & 97 & \\
\hline & Poor & $41(12.8 \%)$ & $0(0.0)$ & 41 & \\
\hline
\end{tabular}




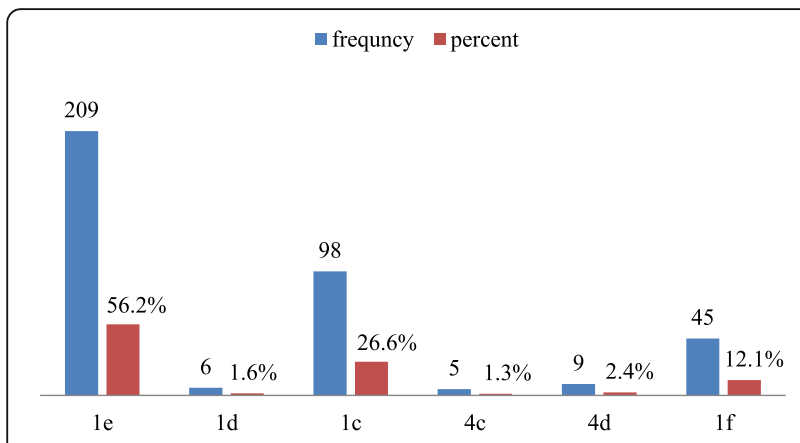

Fig. 1 Type of ART medication used among HIV positive clients in Fre Semaetat primary Hospital Hospital Hawzen,Tigray, Ethiopia, 2019

and negative patients since the introduction of Isoniazid [15]. The overall prevalence of IPT utilization among HIV positive clients used ART medication was found to be $(62.1 \%)$. This finding was lower than from a retrospective study conducted in Arbaminch Hospital (68\%) [13]. However, our finding was higher compared with a cross-sectional descriptive study studies conducted in Tigrai 20\% [16], a qualitative study was done in AddisAbaba $30 \%$. Purposive sampling technique was carried out to select the participants based on exposure to their patients in all circumstances $[17,18]$. In addition, Addis Ababa among 14 public health facilities A. A (77\%) [19], Prospective cohort done in Cambodia (78\%) [20], and a cross-sectional study conducted in Swaziland (89.4\%) [21]. However, higher than studies done in south Ethiopia (50.9\%) and South Africa (69\%) [13, 22]. This difference might be due to the lack of reinforcement by local health officials and stakeholders working in TB was affecting the implementation of the IPT policy. The success of IPT implementation is mainly dependent on continuous capacity building and monitoring. Health providers perceived that insufficient attention is being given to IPT by responsible bodies. In some hospitals sensitization workshops, technical training, and operational guidelines were not provided [16, 23]. Moreover,

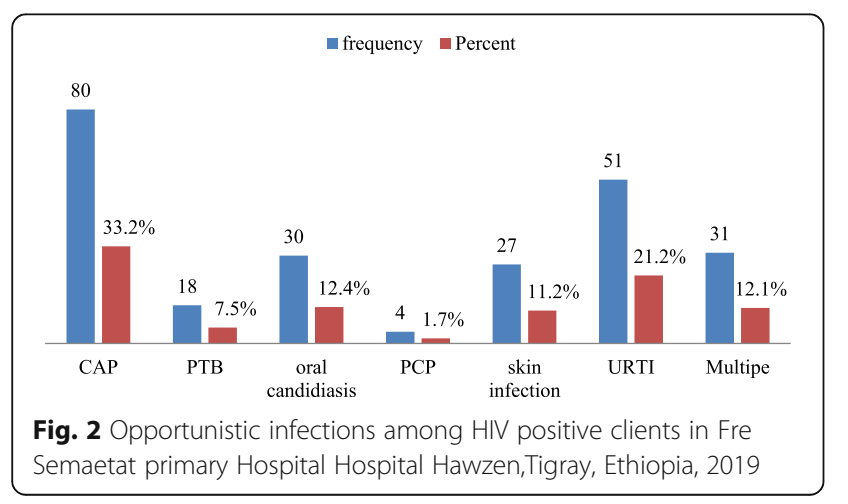

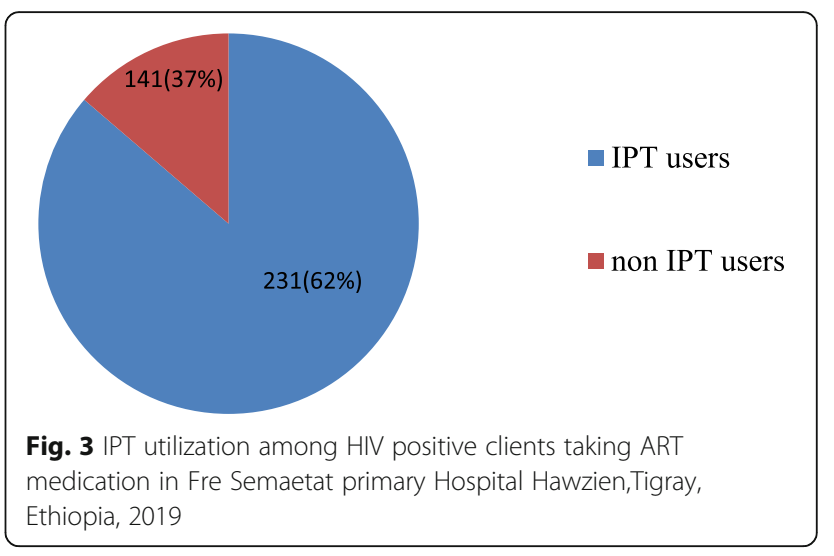

the study design and sampling techniques of the studies might be contributed to the difference. Therefore, to increase the IPT implementation and scale-up program clients' awareness should be increased about the adherence through counseling and increased knowledge patient's awareness of the importance of INH and TB and HIV association and its severity.

In this study, among the IPT utilized participants, $4.8 \%$ of them were developed tuberculosis. This finding was similar to a study done in Jimma University medical center, Ethiopia (3.78\%) [14]. However, this study was higher compared with retrospective cohort studies conducted in Ethiopia Jimma, (2.7\%) [24], and Zimbabwe (0\%) [25].

In our study, the proportion of TB developed individuals among HIV positive clients who took and completed IPT for 6 months was 2 (15.40\%). This finding was higher than from the study done at Arbaminch hospital $(8.7 \%)$ whereas from those who didn't taken IPT $5(9.80 \%)$ study participants had acquired TB infection which was lower than the study done at Arbaminch hospital $(27.80 \%)$ those difference may be due to sampling size difference, awareness, and information [13]. However, this indicates that the completion of IPT in HIV infected clients significantly reduced TB incidence by $69.2 \%$ when compared to those who were developed TB before completing their IPT $11(84.6 \%)$. Moreover, IPT is one of the key interventions recommended by WHO in 1998 to reduce the burden of TB in PLHIV; yet implementation of IPT had been very low in different countries [26].

In this study, $18(4.80 \%)$ study participants had developed TB after initiated of ART that was higher than the study done among HIV-infected patients receiving medical care at 29 public clinics in Rio de Janeiro, Brazil (1.4\%) [27]. This difference may be due to sampling size differences, knowledge and awareness. Lack of training on INH and no one showing responsibility for monitoring the program are the commonly mentioned reasons for low prescription 
Table 3 Bivariate and multivariable analysis for IPT utilization among HIV positive clients who use ART medication in Fre Semaetat primary Hospital Hawzien, Tigray, Ethiopia from April to August 2019 ( $N=372)$

\begin{tabular}{|c|c|c|c|c|c|c|c|}
\hline \multirow[t]{2}{*}{ Variables } & \multirow[t]{2}{*}{ Category } & \multicolumn{2}{|c|}{ IPT utilization } & \multirow[t]{2}{*}{$\operatorname{COR}(95 \% \mathrm{Cl})$} & \multirow{2}{*}{$\begin{array}{l}P \text { - } \\
\text { value }\end{array}$} & \multirow[t]{2}{*}{$\mathrm{AOR}(95 \% \mathrm{Cl})$} & \multirow[t]{2}{*}{$P$-value } \\
\hline & & No & Yes & & & & \\
\hline \multirow[t]{2}{*}{ Sex } & Male & 40 & 159 & $3.705(1.836,7.478)$ & 0.000 & $0.034(0.015,0.077)$ & $0.000^{*}$ \\
\hline & Female & 11 & 162 & 1 & & 1 & \\
\hline \multirow[t]{4}{*}{ Age } & $0-14$ & 3 & 13 & $2.402(0.636,9.077)$ & 0.196 & $0.967(0.147,6.364)$ & 0.972 \\
\hline & $15-24$ & 12 & 23 & $5.431(2.383,12.377)$ & 0.000 & $2.998(0.676,13.298)$ & 0.149 \\
\hline & $25-34$ & 14 & 55 & $2.650(1.274,5.508)$ & 0.009 & $2.242(0.950,5.291)$ & 0.065 \\
\hline & $>=35$ & 22 & 230 & 1 & & 1 & \\
\hline \multirow[t]{2}{*}{ Marital status } & Married & 25 & 259 & $0.456(0.267,0.780)$ & 0.004 & $0.335(0.140,0.806)$ & $0.016^{*}$ \\
\hline & Single & 26 & 62 & 1 & & 1 & \\
\hline \multirow[t]{2}{*}{ Social drug use } & Yes & 14 & 35 & 1 & & 1 & \\
\hline & No & 37 & 286 & $3.092(1.523,6.277)$ & 0.002 & $0.541(0.214,1.369)$ & 0.195 \\
\hline \multirow[t]{2}{*}{ Cpt } & Yes & 14 & 277 & $0.060(0.030,0.120)$ & 0.000 & 8.693(3.600,20.99) & $0.000^{*}$ \\
\hline & No & 37 & 44 & 1 & & 1 & \\
\hline \multirow[t]{2}{*}{ Analgesics } & Yes & 47 & 243 & $3.772(1.317,10.80)$ & 0.130 & $3.592(1.162,11.109)$ & $0.026^{*}$ \\
\hline & No & 4 & 78 & 1 & & 1 & \\
\hline \multirow[t]{2}{*}{ Opioid } & Yes & 23 & 125 & $0.776(.482,1.40)$ & 0.405 & $0.311(0.112,0.868)$ & 0.026 \\
\hline & No & 28 & 196 & 1 & & 1 & \\
\hline \multirow[t]{2}{*}{ Non-opioid } & Yes & 24 & 119 & $0.663(0.366,1.20)$ & .175 & $0.284(0.102,0.790)$ & 0.016 \\
\hline & No & 27 & 202 & 1 & & 1 & \\
\hline \multirow[t]{2}{*}{ Antifungal } & Yes & 14 & 45 & $2.262(1.136,4.509)$ & 0.020 & $1.487(0.662,3.341)$ & 0.337 \\
\hline & No & 37 & 276 & 1 & & 1 & \\
\hline
\end{tabular}

CI Confidence Interval, COR Crude Odds Ratio, AOR Adjusted Odds Ratio * $=p$ value $<0.05^{*}$ statistically significant with IPT utilization $p \leq 0.05$

rate. Care providers opinion for factors affecting adherence and utilization of IPT.

\section{Conclusion}

The utilization of INH among people living with HIV in Fresemaetat primary hospitals was low. Lack of appointment per demand, lack of training, busy clinic and nonsustainabledrug supply and lack of trust when the supply is inconsistent after initiation for few months were the possible reasons for the low utilization rate of IPT. Therefore, Increase provider $\mathrm{s}$ knowledge on IPT through training and monitoring and evaluation,consistent IPT delivery system and introducing new tools into practice in line with the global plan to stop TB is important.

\section{Abbreviations}

ART: Antiretro Viral Therapy; BMI: Body Mass Index; CPT: Co-Trimexazol Prophylaxis Therapy; CSA: Central Statistical Agency; HIV: Human Immune Virus; IPT: Isoniazid Prophylaxis Therapy; SPSS: Statistical Package for Social Science; TB: Tuberculosis; WHO: World Health Organization

\section{Acknowledgments}

We are grateful to Adigrat University College of Health and Medical Science, Department of Public Health and study participants for their contribution to this research work
Authors' contributions

HL designed the study, collected, entered, did lab work, analyzed, interpreted the data, and prepared the draft manuscript. $A G, H G$, and $H G$, contributed to data analysis, interpretation and prepared the manuscript for publication. All authors read and approved the final manuscript.

\section{Funding}

Not applicable.

\section{Availability of data and materials}

The datasets used and analyzed during the current study are available from the corresponding author on reasonable request.

\section{Ethics approval and consent to participate}

Ethical approval was sought from Adigrat University College of Health and Medical Science, and Health Research Ethics Review Committee (HRERC) and was granted accordingly with the reference number. Official support letters were submitted to the study Hospital. Informed written consent was obtained from each study participant. Participants were also informed that they are free to withdraw from the study at any time and their medical records were kept strictly confidential.

\section{Consent for publication}

Individual data such as images and videos did not accompany this particular manuscript and hence consent for publication is not applicable.

\section{Competing interests}

The authors declare that they have no competing interests. 


\section{Author details}

'Department of Medical Laboratory Sciences, College of Medicine and Health Sciences, Adigrat University, Adigrat, Ethiopia. ${ }^{2}$ Department of Public Health, College of Medicine and Health Sciences, Adigrat University, Adigrat, Ethiopia.

Received: 15 November 2019 Accepted: 15 April 2020

Published online: 17 June 2020

\section{References}

1. World Health Organization. Global Tuberculosis Report. 2018. http://apps. who.int/iris/bitstream/handle/10665/274453/9789241565646-eng.pdf. Accessed 19 Oct 2019.WHO, global tuberculosis report 2017.

2. Ethiopia Country/Regional Operational Plan (COP/ROP) 2016 Strategic Direction Summary April 21, 2016, page (29).

3. Federal Ministry of Health Department of Public Health. Guidelines for Clinical Management of TB/HIV related conditions In Nigeria 2nd edition.

4. Mark FC. INH preventive therapy (IPT) in HIV-infected south African children. Southern Afr J of HIV Med. 2011;12:2.

5. World Health Organization (WHO). Guidelines for Intensified Case-Finding and Isoniazid Preventive Therapy for People Living with HIV in ResourceConstrained Settings. Geneva: WHO; 2011.

6. Ayele HT, van Mourik MSM, Debray TPA, Bonten MJM. Isoniazid Prophylactic Therapy for the Prevention of Tuberculosis in HIV Infected Adults: A Systematic Review and Meta-Analysis of Randomized Trials. PLoS One. 2015; 10(11):e0142290

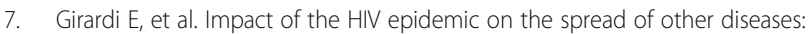
the case of tuberculosis. AIDS. 2000;14(3):S47-56.

8. Cruciani M, et al. The impact of HIV1 on infectiousness of tuberculosis: a meta-analysis. Clin Infect Dis. 2001;33:1922-30.

9. $\mathrm{WHO}, \mathrm{Global}$ tuberculosis report 2015 .

10. TB/HIV research priorities in resource-limited settings: report of an expert consultation. Geneva, World Health Organization, 2005 (WHO/HIV/2005.03)

11. World Health Organization. Global tuberculosis report 2015. 2015 October. Report No.: WHO/HTM/TB/2015.22.P 85. [Cited 2019 Sep 26]. Available from: https://www.who.int/tb/publications/global_report/gtbr15_main_text.pdf.

12. World Health Organization. A guide to monitoring and evaluation of collaborative TB/HIV activities: 2015 revision. Geneva: World Health Organization; 2015. Available at: http://www.who.int/tb/publications/ monitoring-evaluation-collaborative-tb-hiv/en/.

13. Abossie A, Yohanes T. Assessment of isoniazid preventive therapy in the reduction of tuberculosis among ART patients in Arba Minch Hospital, Ethiopia. Therapeutics Clin Risk Manage. 2017;13:361-6. https://doi.org/10. 2147/TCRM.S127765

14. Sabasaba A, Mwambi H, Somi G, Ramadhani A, Mahande MJ. Effect of isoniazid preventive therapy on tuberculosis incidence and associated risk factors among HIV infected adults in Tanzania: a retrospective cohort study. BMC Infect Dis. 2019;19:62. https://doi.org/10.1186/s12879-019-3696.

15. Green S., Higgins P J., Alderson T P., Clarke M., Mulrow D C., and Oxman D A., "Cochrane Handbook: Cochrane Reviews: Ch 8: Assessing risk of bias in included studies," in Cochrane Handbook for: Systematic Reviews of Interventions, 2011; 1 (6). 3-10.

16. Teklay G, Teklu T, Legesse B, Tedla K, Klinkenberg E. Barriers in the implementation of isoniazid preventive therapy for people living with HIV in northern Ethiopia: a mixed quantitative and qualitative study. BMC Public Health. 2016:16:840. https://doi.org/10.1186/s12889-016-3525-8.

17. Wesen A, Mitike G. Provision and awareness for isoniazid preventive therapy among PLHIV in Addis Ababa, Ethiopia. BMC Int Health Hum Rights. 2012; 12(1):2.

18. Denegetu AW, Dolamo BL. Tuberculosis case finding and isoniazid preventive therapy among people living with HIV at public health facilities of Addis Ababa, Ethiopia: a cross-sectional facility based study. BMC Public Health. 2014;14:52

19. Semu M, Fenta TG, Medhin G, Assefa D. Effectiveness of isoniazid preventative therapy in reducing individuals incidence of active tuberculosis among people living with HIV/ AIDS in public health facilities of Addis Ababa, Ethiopia: a historical cohort study. BMC Infect Dis. 2017;17:5.

20. Van Griensven J, Choun K, Chim B, Thai S, Lorent N, Lynen L. Implementation of isoniazid preventive therapy in an HIV clinic in Cambodia: high rates of discontinuation when combined with antiretroviral therapy. Tropical Med Int Health. 2015;20(12):1823-31. https://doi.org/10. 1111/tmi.12609.

21. L.V. Adams, Mahlalela E. A, Talbot M, Pasipamire, S. Ginindza, M. Calnan, S. Haumba. High completion rates of isoniazid preventive therapy among persons living with HIV in Swaziland. Int J Tuberc Lung Dis. 2017;21(10): 1127-32.

22. Oni T, Tsekela R, Kwaza B, Manjezi L, Bangani N, Wilkinson KA, et al. A Recent HIV Diagnosis Is Associated with Non-Completion of Isoniazid Preventive Therapy in an HIV-Infected Cohort in Cape Town. PLoS One. 2012;7(12):e52489 [PubMed: 23285064]

23. Mindachew M, Deribew A, Memiah P, Biadgilign S. Perceived barriers to the implementation of isoniazid preventive therapy for people living with HIV in resource-constrained settings: a qualitative study. Pan Afr Med J. 2014;17:26.

24. Assebe LF, Reda HL, Wubeneh AD, Lerebo WT, Lambert SM. The effect of isoniazid preventive therapy on incidence of tuberculosis among HIVinfected clients under pre-ART care, Jimma, Ethiopia: a retrospective cohort study. BMC Public Health. 2015;15:346. https://doi.org/10.1186/s12889-0151719-0

25. World Health Organization. Policy statement on preventive therapy against TB in PLHIV: Report of a meeting held in Geneva 18-20 February. In: World Health Organization Global TB Programme and UNAIDS; 1998.

26. Nyathi S, Dlodlo RA, Satyanarayana S, Takarinda KC, Tweya H, Hove S, et al. Isoniazid preventive therapy: uptake, incidence of tuberculosis and survival among people living with HIV in Bulawayo, Zimbabwe. PLoS One. 2019; 14(10):e0223076. https://doi.org/10.1371/journal.pone.0223076.

27. Golub JE, Saraceni V, Cavalcante SC, et al. The impact of antiretroviral therapy and isoniazid preventive therapy on tuberculosis incidence in HIVinfected patients in Rio de JaneiroBrazil. AIDS. 2007;21(11):1441-8. https://doi.org/10.1097/QAD.0b013e328216f441.

\section{Publisher's Note}

Springer Nature remains neutral with regard to jurisdictional claims in published maps and institutional affiliations.
Ready to submit your research? Choose BMC and benefit from:

- fast, convenient online submission

- thorough peer review by experienced researchers in your field

- rapid publication on acceptance

- support for research data, including large and complex data types

- gold Open Access which fosters wider collaboration and increased citations

- maximum visibility for your research: over $100 \mathrm{M}$ website views per year

At $\mathrm{BMC}$, research is always in progress.

Learn more biomedcentral.com/submissions 